\title{
The role of the nurse in the treatment of children \\ with non-suicidal self-injurious behaviour, autism spectrum disorder and features of the application of therapy in the child psychiatry department
}

Metka Knez, Bojan Sladojević, Neža Oblak, Ana Gorenc, Aljaž Novak

\section{Izvleček}

Pri nekaterih otrocih se med procesom odraščanja srečamo s številnimi oblikami ne samomorilnega samopoškodbenega vedenja in z različnimi stopnjami spektroavtističnih motenj. Zaradi tveganja dodatne poškodbe ali neuspešnosti pri vključevanju v življenjsko družbeno okolje moramo takšnega otroka sprejeti na oddelek za otroško psihiatrijo, kjer sta $z$ vidika medicinske sestre oziroma zdravstvenega tehnika pomembna ustrezen pristop in nadaljnja pravilna obravnava med celotnim zdravljenjem v bolnišnici.

$\checkmark$ prispevku predstavljamo nesamomorilno samopoškodbeno vedenje, spektroavtistično motnjo ter vlogo medicinskih sester in zdravstvenih tehnikov pri bolnišnični obravnavi otroka.

Uporabili smo opisno metodo dela. Vključili smo strokovno in znanstveno literaturo iz podatkovnih baz Medline, CINAHL in Cohrane Library ter COBBIS. Uporabili smo naslednje ključne besede in besedne zveze: »avtoagresija «, »duševna motnja«, »samopoškodovanje «, »nesamomorilnost«, »apliciranje terapije«, »spektroavtistična motnja«, »komorbidnost«. Medicinske sestre in zdravstveni tehniki lahko hospitaliziranemu otroku z ustreznim znanjem zagotovimo učinkovito in celostno obravnavo, ki omogoča, da se čim bolj približamo otrokovi stopnji sposobnosti sodelovanja in upoštevamo standarde zdravstvene nege.

Ključne besede: otroška psihiatrija, samopoškodbeno vednje, spektroavtistična motnja, dajanje zdravil, medicinska sestra.

\section{Abstract}

In some children, many forms of non-suicidal self-injurious behaviour and varying degrees of autism spectrum disorders can be encountered during the process of growing up. Because of the risk of additional injury or unsuccessful integration into the social environment, the child often requires hospitalisation in the Department of Adolescent and Child Psychiatry. From the nurse's viewpoint, it is very important to adopt the correct approach and subsequent treatment throughout the child's hospitalisation.

This article presents non-suicidal self-injurious behaviour, autism spectrum disorders and the role of the nurse in the treatment of the hospitalised child.

In the article, we used the descriptive work method. We included professional and scientific literature from the Medline, CINAHL, Cochrane Library and COBBISS databases. We used the following key words and phrases: autoaggression, mental disorder, self-injury, non-suicidal behaviour, application of therapy, autism spectrum disorders and comorbidity.

Nurses with the appropriate knowledge can assure the hospitalised child effective and holistic treatment, during which it is important to draw as near as possible to the level of the child's ability to cooperate while adhering to the healthcare standard.

Key words: child psychiatry, self-injurious behaviour, autism spectrum disorder, application of therapy, nurse. 


\section{Uvod}

Ko se končuje obdobje otroštva, otroci vstopijo v obdobje mladostništva, ki je priprava na odraslost. Mladostniki se srečujejo z neznanimi situacijami in čedalje večjimi zahtevami. Morajo se prilagoditi in najti svoje interese, sprejeti svoje značilnosti, tako osebnostne kot telesne, ter se naučiti čim bolj samostojnega življenja.

Velike spremembe na telesnem, duševnem in socialnem področju od mladostnika zahtevajo pomembne prilagoditve, ki jim pogosto niso kos (1). Četrtina mladih v Evropski uniji se je že kdaj v življenju samopoškodovala, približno desetina mladostnikov pa naj bi to vedenje izvajala aktivno. Poznamo različne oblike samopoškodbenega vedenja. Najpogosteje gre za rezanje ali zbadanje kože, žganje, praskanje delno zaceljenih ran in udarjanje z rokami ali glavo ob trde predmete (2). Samopoškodbeno vedenje se pogosto pojavi v kontekstu depresivnega razpoloženja, anksioznosti in vedenjskih težav, pogosto pa je v ozadju travmatski dogodek iz preteklosti (3). Samopoškodbeno vedenje pogosto ugotavljamo tudi pri mladostnikih s spektroavtistično motnjo (2).

\section{Nesamomorilno samopoškodbeno vedenje}

Z medicinskega vidika lahko nesamomorilno samopoškodbeno vedenje (NSSV) razdelimo na hudo, stereotipno, kompulzivno in impulzivno NSSV. Pri mladostnikih se največkrat srečujemo z impulzivnimi oblikami samopoškodbenega vedenja. Med najpogostejše uvrščamo površinsko rezanje ali zbadanje kože na rokah ali drugih delih telesa, ožiganje telesa, pretiran "piercing« ali tetoviranje, trganje delno zaceljenih ran in udarjanje z glavo ali drugimi deli telesa ob trde površine (4).

\section{Dejavniki tveganja}

Dejavnik tveganja za NSSV je spol otroka. Dokazano je, da je samopoškodbeno vedenje brez samomorilnega namena in poskusi samomora bolj pogosto pri ženskah. NSSV redko srečamo pred nastopom pubertete (2). Ugotavlja se, da je NSSV bolj povezano z biološkimi spremembami v času pubertete kot s posameznikovo kronološko starostjo (4). Samomorilnost in NSSV sta pogostejša pri istospolno usmerjenih, kar je povezano s skrbjo glede spolne usmerjenosti in samopodobe (5). Eden glavnih dejavnikov tveganja NSSV so tudi duševne motnje. Najbolj pogoste so motnje razpoloženja, anksiozne motnje, odvisnost od psihoaktivnih snovi, motnje hranjenja ter motnje vedenja in osebnosti (4). NSSV je prisotno tudi pri mladostnikih z motnjami avtističnega spektra ter tudi pri duševno manj razvitih otrocih (2). Bolj pogosto je pri mladostnikih, pri katerih osebnostni razvoj poteka moteno (4). Predvsem gre za slabše sposobnosti reševanja problemov, impulzivnost, manjše prilagoditvene sposobnosti in slabše odnose $z$ drugimi (2). Pomemben dejavnik tveganja so slabši odnosi znotraj ožje družine, revščina in družinska anamneza samomorilnega ali samopoškodbenega vedenja, nasilja in zlorab v družini. Otroci z NSSV imajo pogosteje tudi težave $v$ šoli (4). Socialni prenos NSSV je zelo pogost v manjših, povezanih krogih mladostnikov, zlasti pri dekletih (2).

NSSV se pogosto pojavi v kontekstu depresivnega razpoloženja, anksioznosti, vedenjskih težav, neredko pa je v ozadju tudi travmatski dogodek iz preteklosti (spolna ali telesna zloraba, nasilje v družini). Mladostniki pogosto poročajo o občutkih kronične praznine, odtujenosti in izolacije. Poročajo tudi o brezupu, nemoči, občutku, da so drugim v breme, nepriljubljenosti in slabi samopodobi (3).

\section{Zdravstvenonegovalna vloga na področju preprečevanja samopoškodbenega vedenja}

Ob sprejemu otroka z NSSV v bolnišnico je zelo pomembno, da pridobimo njegovo zaupanje. Medicinska sestra otroku in staršem ob prihodu razkaže oddelek ter predstavi dejavnosti, oddelčna pravila in dnevni red. Skupaj sestavijo načrt nadaljnje obravnave z jasnimi cilji. Pravila morajo biti predstavljena razumljivo. Otroku postavimo jasne meje, hkrati pa mu dovolimo, da občuti čustva (1).

Pri namestitvi na oddelek ob prisotnosti staršev in otroka opravimo pregled otrokovih osebnih predmetov, takoimenovano higiensko vizito. Higiensko vizito opravita dve medicinski sestri/ zdravstvena tehnika (MS/ZT), v posebnih primerih pa je prisoten tudi zdravnik. Preveriti moramo vse, kar otrok prinese s seboj ali dobi na oddelku, to so šolske potrebščine, pripomočki za osebno higieno, oblačila in druge osebne stvari. Če je v otrokovi anamnezi večkrat prisotno samopoškodbeno vedenje, se mora otrok sleči do spodnjega perila, s čimer preprečimo, da bi nevaren predmet skril pod oblačila. Odstraniti moramo vse očitno ogrožajoče oziroma potencialno ogrožajoče ostre predmete (šilčke, škarje, šestila, britvice, ravnila ipd.), vrvice, pas za hlače, priključke slušalk, polnilce za mobilne telefone, vžigalnike in podobno. S tem namreč preprečimo morebitne samopoškodbene ali celo samomorilne dogodke.

Naloga MS/ZT je, da poskrbi za spodbudno in optimistično vzdušje ter nudi občutek sprejetosti. Med zdravljenjem mladostnik potrebuje podporo in pohvalo pri izvajanju različnih dejavnosti (6), pri čemer MS/ZT v otroku vzbuja občutek, da razume njegovo nemoč in obup ter mu pomaga razviti občutek vrednosti in samospoštovanja. $V$ odnosu do otroka je vseskozi potreben spoštljiv in razumevajoč odnos (1).

MS/ZT večkrat postane tudi otrokova zaupnica. Če je v stiski, je ob otroku prva, saj je na oddelku prisotna med celotnim bivanjem $v$ bolnišnici. Večina stisk nastopi v popoldanskih ali večernih urah, lahko tudi v nočnem času in zgodnjih jutranjih urah. Izrednega pomena je sposobnost opazovanja 
MS/ZT, da pri otroku zazna spremembe $v$ razpoloženju in s tem prepreči ponovne poskuse samopoškodbenega vedenja. Prav je, da se takrat z otrokom pogovori z veliko mero empatičnosti, razumevanja in neobsojajoče. Zbrano naj ga posluša ter nikakor ne obsoja in kritizira. S pogovorom ga skuša pomiriti in ga zamotiti, lahko preusmeri pozornost z igranjem družabnih iger ali drugimi dejavnostmi, ki so otroku blizu in jih ima rad. Ob hujši stiski za pomiritev uporabi deeskalacijske tehnike (nabor metod in pristopov, namenjenih obvladovanju jeze, agitacije in preprečevanju agresivnega vedenja). O stiski mora čim prej obvestiti lečečega zdravnika oziroma dežurnega pedopsihiatra. Obdobje mladostništva je za otroka in tudi njegovo ožjo in širšo okolico velik izziv. Otroci se v življenju srečujejo z različnimi stiskami, ki jih ne znajo razrešiti sami, zato se pogosto zatečejo k alternativnim načinom reševanja težav, med katerimi je tudi samopoškodovanje. Ključnega pomena je, da otroka z znaki NSSV ne prezremo, ampak ga skušamo odkriti v zgodnji fazi in mu nuditi pomoč $v$ različnih oblikah (2).

\section{Spektroavtistična motnja}

Spektroavtistična motnja (SAM) je razvojnonevrološka motnja, za katero so značilni vedenjske posebnosti na področju komunikacije, socializacije in usmerjenih interesov ter togo, stereotipno vedenje (7). Težave, ki so povezane s SAM, vztrajajo in se v mladostništvu in odraslosti pogosto ojačajo (8).

SAM po merilih Diagnostičnega in statističnega priročnika o duševnih motnjah (DMS-V) opredelimo glede na prisotnost naslednjih meril:

- težave v socialni interakciji in komunikaciji, ki se kažejo na več področjih;

- usmerjeno, ponavljajoče se oziroma stereotipno vedenje (senzorna preobčutljivost);
- pojav simptomov v zgodnjem otroštvu;

- simptomi pomembno ovirajo posameznika v vsakdanjem življenju;

- težave niso posledica nižjih intelektualnih sposobnosti.

\section{Komunikacija in socializacija}

Motnja v socialni interakciji in komunikaciji se kaže v odsotnosti ali pomanjkanju razvoja spontane socialne interakcije, govorno-jezikovne komunikacije (ekspresivni in receptivni jezik, eholalija, nenavaden razvoj z vidika tempa, ritma ali melodije govorjenega jezika) in neverbalne komunikacije (razumevanje in uporaba nejezikovnih prvin jezika) ter v razvijanju, vzpostavljanju in razumevanju medosebnih odnosov (nerazumevanje vedenja in govorice telesa, neprepoznanje namena). Izraz nesposobnosti komuniciranja z okoljem so pogosto neželeni vedenjski vzorci (stereotipije, agresija). Okoliščine si pogosto razlagajo dobesedno, zato so videti socialno nerodni in čudaški, zaradi neupoštevanja socialnih pravil pogosto tudi nevljudni in nesramni $(9,10)$. Prvi znak za zaskrbljenost staršev in strokovnjakov je pogosto zaostanek v govornem razvoju (11).

\section{Usmerjeni interesi in stereotipno vedenje}

Prisotni so nenavadni in omejeni interesi ali za starost običajni interesi, ki so pretirano intenzivni. Otroci jih zadovoljujejo lahko ure dolgo in ne vključujejo drugih ljudi (vlaki, knjige, dinozavri, vulkani, vesolje, ventilatorji in podobno). Pogosto so prisotni stereotipni gibi rok in prstov, mahanje z rokami, skakanje, guganje, prestopanje in vrtenje. Večinoma so senzorno preobčutljivi na zvok, vonj, dotik, vid in okus. Stisko povzročajo spremembe dnevne rutine, spremembe okolja in tudi prehajanje med aktivnostmi. Togi so v mišljenju in vedenju (9).

Zgodnje odkrivanje motnje in ustrezna obravnava otrok s SAM lahko bistve- no prispevata k boljši kakovosti življenja posameznika s SAM v odraslosti; izboljšajo se posameznikove možnosti za samostojnost, dejavno vključevanje v družbeno življenje, razvijanje potencialov in celostni doprinos k družbi (12). Prepoznava otrok s SAM omogoča, da je otrok usmerjen $v$ ustrezne terapevtske obravnave. Tudi staršem nudimo psihoedukacijo in svetovanje, otroke pa vključimo v ustrezne vzgojno-izobraževalne programe (11).

\section{Soobolevnosti}

Skoraj tri četrtine vseh otrok in adolescentov s SAM ima spremljajoče duševne motnje, ki prispevajo k slabšanju njihovega kliničnega stanja in neugodno vplivajo na kakovost življenja celotne družine. Najpogostejše spremljajoče motnje so depresija, motnje aktivnosti in pozornosti (ADHD), motnje spolne identitete, obsesivno-kompulzivna motnja, motnje spanja, Tourettov sindrom in tiki. Pogosti spremljajoči simptomi so neučinkovito uravnavanje čustev, motnje razpoloženja, samopoškodovanje in tesnoba (13). Če se otrok ne odziva na nefarmakološke intervencije ali če ima vedenje negativen vpliv, je indicirano zdravljenje z zdravili. Če se problematično vedenje odziva na zdravila, gre za zdravljenje simptomov in ne za zdravljenje same motnje. Zdravila, ki se jih najpogosteje uporabljamo pri avtizmu, so antipsihotiki, stimulansi, antidepresivi, stabilizatorji razpoloženja, anksiolitiki in zdravila za spanje (11).

\section{Vloga in pristop medicinske sestre pri otroku $z$ duševno motnjo v zvezi z dajanjem zdravil}

Med poklicne dejavnosti medicinskih sester uvrščamo tudi pripravo in dajanje zdravil (14). Dajanje zdravil je ena glavnih nalog medicinskih sester ter pomeni oskrbo bolnikov s predpisanimi učinkovinami $v$ diagnostič- 
ne namene ter za zdravljenje oziroma preprečevanje bolezenskih stanj. Vsi odgovorni v procesu predpisovanja in dajanja zdravil morajo biti seznanjeni z zdravili, s katerimi imajo opravka. Poznati morajo osnovne značilnosti zdravil, med katere uvrščamo sestavo, farmakološko obliko, indikacije, kontraindikacije, način uporabe, odmerjanje in posebna opozorila. Splošna znanja o omenjenih področjih MS/ZT prejmejo med srednješolskim, višješolskim in univerzitetnim izobraževanjem. Izpopolnjevanje in nadgrajevanje znanja je potrebno tudi po zaposlitvi (15). Panić in Vidmar (16) poleg usposabljanja in izobraževanja poudarjata pomen razvijanja in uporabe protokolov, predvsem zaradi različnih dejavnikov, ki bi utegnili ogroziti otrokovo varnost.

\section{Pravilo »12P《}

Pri dajanju zdravil, mora medicinska sestra upoštevati dvanajst pravil (»12P«), s čimer otroku zagotavlja večjo stopnjo varnosti. Pravila pri dajanju zdravil so:

1. pravo zdravilo,

2. pravi odmerek,

3. pravi čas,

4. pravilen način,

5. pravi bolnik,

6. pravi razlog,

7. pravilo informiranja bolnika,

8. pravilo dokumentiranja,

9. pravilo odklonitve,

10. pravilo opazovanja,

11. pravilo vrednotenja,

12. preverjanje datuma uporabnosti (17).

\section{Posebnosti pri dajanju zdravil}

Dajanje zdravil otrokom je ena večjih odgovornosti medicinskih sester. Medicinske sestre so otroku in staršem v oporo ter jih poučujejo o učinkovanju zdravila ter tudi presnavljanju in gibanju zdravila v organizmu.

Medicinska sestra je odgovorna za pravilno in varno dajanje zdravil, kar zahteva posebne spretnosti. Pri otroku moramo doseči sodelovanje ter ga ustrezno pripraviti, da je dogodek zanj čim manj travmatičen. Medicinska sestra mora glede na otrokovo starost in razvojno stopnjo poznati otrokove telesne značilnosti in psihološke potrebe (18).

Otroci so radovedni, zanima jih njihovo zdravje in zdravila, a pogosto ne vedo, na koga naj se obrnejo z vprašanji. Pravilno je, da otrok sprašuje o svojem zdravju in o zdravilih, odgovori na njegova vprašanja pa morajo biti preprosti in pošteni. Pri tem moramo upoštevati otrokovo starost, saj včasih potrebujejo več razlage, in jih pozneje tudi povprašati, ali so povedano razumeli. Starejši otroci zmorejo razumeti informacije o svojem zdravju. Otrok naj o svojih zdravilih ve sledeče: ime zdravila, zakaj ga uporabljamo in kako deluje, kako ga pravilno uporabljamo, kdaj ga vzamemo in kako dolgo ga uporabljamo, kaj storimo, če pozabimo vzeti odmerek, kateri neželeni učinki se lahko pojavijo in komu naj povemo o njih (19).

Postopek vnosa zdravil per os zajema več korakov. Pripraviti moramo potrebne pripomočke (voziček z zdravili, plastične prozorne škatlice za zdravila, temperaturni list, papirnate brisače in tekočino za bolnika). Pri zdravilu moramo pregledati rok uporabe in upoštevati pravila »12P《. Zdravilo damo $v$ plastično prozorno škatlico v prisotnosti bolnika. Preverimo bolnikovo poznavanje zdravila in možnosti zapletov (alergije). Zdravila dajemo ob točno določeni uri, glede na to, ali zdravnik zdravilo predpiše enkrat, dvakrat, trikrat ali večkrat dnevno. Zdravila ne pripravljamo za večkratno dajanje oz. vnaprej, temveč za vsak odmerek posebej. Posebno pozornost namenjamo zdravilom, ki dražijo želodčno sluznico. Vedno poskrbimo, da ima otrok dovolj tekočine. O morebitnih zapletih takoj obvestimo lečečega ali dežurnega zdravnika.

Zdravstveno osebje se vsakodnevno srečuje s pripravo in dajanjem predpisanih zdravil. Pri dajanju moramo biti pozorni na različne odklone. Naša pozornost mora biti še toliko večja, saj imamo opravka s tvegano skupino otrok, tj. otroki z različnimi duševnimi motnjami, kot so osebnostne motnje in motnje hranjenja. Pri vsakem peroralnem dajanju zdravila upoštevamo »12P«. Poleg tega smo pozorni, da vsakič preverimo, ali je otrok pravi. Posebnost oddelka je tudi, da otroci ne nosijo identifikacijskih zapestnic. Ko se prepričamo, da je otrok pravi, preverimo, ali je otrok zdravilo resnično zaužil. To storimo tako, da dobro pregledamo otrokova usta in se prepričamo, da ni zdravila skril pod jezik, na nebo ali za dlesen. Da se izognemo takšnim situacijam, damo zdravilo na žlico in skrbno nadzorujemo zaužitje ter smo ob otroku toliko časa, da predpisano zdravilo tudi dejansko zaužije.

Zdravila per os pripravljamo hkrati za enega otroka in za eno predpisano dajanje. Nikoli ne pripravljamo hkrati zdravil za različne otroke, čeprav imajo morda predpisano enako zdravilo. Zdravil, ki smo jih že odložili v otrokovo posodico in jih otrok ni zaužil zaradi različnih razlogov, (naprimer odklonitve), ne vračamo v oddelčni depo, kjer hranimo zdravila, ampak jih zavržemo. Pripravljena zdravila mora otrok zaužiti ob prisotnosti zdravstvenega delavca. Zdravil, ki smo jih prinesli otroku, ne puščamo brez nadzora. Po drobljenju ali rezanju tablet posodico izplaknemo pod tekočo vodo in obrišemo do suhega.

\section{Zaključek}

Mladostništvo je pomembna izkušnja. Pri otrocih s SAM so ključnega pomena zgodnja prepoznava, ustrezno 
zdravljenje in nadaljnje usmerjanje, ki izboljšajo kakovost življenja. Mladostniki se med odraščanjem srečujejo s številnimi stiskami, a jih zaradi slabšega duševnega zdravja ali neučinkovitega spoprijemanja s težavami lahko kažejo s samopoškodovanjem. Kot je za mladostnike nesamomorilno samopoškodbeno vedenje nova možnost in izziv izražanja, tako je tudi za zdravstveno negovalno osebje izziv, da uporabijo različne pristope ter da mladostnike med bolnišničnim zdravljenjem celostno obravnavajo $v$ skladu s predpisanimi protokoli in standardi.

\section{Literatura \\ 1. Kovač S, Brecelj-Kobe M, Rujevič J, Mušič D. Kako voditi pogovor s samomorilno ogroženim otrokom in mladostnikom. Slov Pediatr 2013; 20: 71-7.}

2. Tomaševič A, Radobuljac Drobnič M, Samopoškodovalno vedenje brez samomorilnega namena pri mladostnikih. Medicinski razgledi 2007: 56(3): 323-29.

3. Dolenc B, Kognitivno - vedenjska obravnava samopoškodbenega vedenja v mladostništvu. Psihološka obzorja 29, 21-23.

4. Radobuljac MD. Samomorilno in samopoškodovalno vedenje v otroštvu in mladostništvu. Izbrana poglavja iz psihiatrije: 2020 (V TISKU).

5. Fergusson M, Horwood J, Beautrais AL. Is Sexual Orientatiton Related to Mental Health Problems and Suicidality in Young People? Arch Gen Phychiatry 1999; 56: 876-80.

6. Mušič D. Vloga zdravstvene nege na oddelku Službe za otroško psihiatrijo. Slov Pediatr 2011; 18 : 40-5.

7. Jeličić A. Prepoznava in obravnava avtizma (SAM) v mladostništvu in odraslosti. Zbornik prispevkov konference Avtizem v Sloveniji - kje smo leta 2018? Maribor: Center za sluh in govor 2018: 33.

8. Kranjc J. Odrasli s SAM - Kje smo in kam želimo? Zbornik prispevkov konference Avtizem v Sloveniji - kje smo leta 2018? Maribor: Center za sluh in govor 2018: 34-7.

9. Berložnik N, Černic Gantar A, Pečarič V et al. Navodila za delo z otroki z avtističnimi motnjami v prilagojenem programu z nižjim izobrazbenim standardom. Ljubljana: Ministrstvo za izobraževanje, znanost in šport: Zavod RS za šolstvo, 2014: 4.

10. Brasher S, Stapel-Wax J. Autism for the primary care provider: Importance of early diagnosis and intervention. In: Reeves GC. Advances in family practice nursing. 2nd ed. New York: Elsevier Health Sciences, 2020: 159-68.

11. Pastorino GMG, Operto FF, Coppola G. Pharmacotherapy in autism spectrum disorder: How, when and why. BRAIN. Broad Research in Artificial Intellegence and Neuroscience 2020;11(1).Dosegljivo na: https://lumenpublishing.com/journals/index.php/ brain/article/view/2853

12. Maček J. Otrokz avtizmom. Kritično bolan in poškodovan novorojenček in otrok - razpoznava, zdravljenje in prevoz. Ljubljana: Klinični oddelek za otroško kirurgijo in intenzivno terapijo 2011: 267-71.

13. Subramanyam AA, Mukherjee A, Dave M, Chavda K. Clinical practice guidelines for autism spectrum disorders. Indian Journal of Psychiatry 2019; 61: 254-69.

14. Prestor J, Ažman M, Prelec A, Hajdarević B, Babič D, Benkovič R. Poklicne kompetence in aktivnosti izvajalcev $v$ dejavnosti zdravstvene nege. Ljubljana: Zbornica zdravstvene in babiške nege Slovenije - Zveza strokovnih društev medicinskih sester, babic in zdravstvenih tehnikov Slovenije 2019: 50.

15. Mavsar-Najdenov B. Zagotavljanje varnosti in kakovostni pri dajanju zdravil. 4. dnevi Angele Boškin: Strokovno srečanje: Varnost - rdeča nit celostne obravnave pacienta - Zbornik predavanj. Gost Martuljek: Splošna bolnišnica Jesenice 2011: 48-55.

16. Panić Z, Vidmar L. Zagotavljanje varnosti pri uporabi in aplikaciji zdravil. 4. dnevi Angele Boškin: Strokovno srečanje: Varnost - rdeča nit celostne obravnave pacienta - Zbornik predavanj. Gost Mertuljek: Splošna bolnišnica Jesenice 2011: 63-6. 17. Remškar D. Pravilen način in pot aplikacije zdravil. 24. Mednarodni simpozij o urgentni medicini. Portorož: Slovensko združenje za urgentno medicino 2017: 290-4.

18. James SR, Nelson K, Ashwill J. Nursing care of children: Principles and practice $4^{\text {th }}$ edition. China: Elsevier 2013: 298.

19. Pisk N. Kaj naj otrok ve o svojih zdravilih? In: Pisk N, ed. O pravilni in varni uporabi zdravil, Zdravila in otroci. Slovensko farmacevtsko društvo: Collegium Graphicum, 2008: 21-3.

\section{Metka Knez, dipl. m. s.}

Univerzitetni klinični center Ljubljana Pediatrična klinika, Služba za otroško in mladostniško psihiatrijo, Ljubljana, Slovenija

\section{Bojan Sladojević, dipl. zn.}

Univerzitetni klinični center Ljubljana Pediatrična klinika, Služba za otroško in mladostniško psihiatrijo, Ljubljana, Slovenija

\section{Neža Oblak, dipl. m. s.}

Univerzitetni klinični center Ljubljana Pediatrična klinika, Služba za otroško in mladostniško psihiatrijo, Ljubljana, Slovenija

Ana Gorenc, dipl. m. s. Univerzitetni klinični center Ljubljana Pediatrična klinika, Služba za otroško in mladostniško psihiatrijo, Ljubljana, Slovenija
Aljaž Novak, dipl. zn.

Univerzitetni klinični center Ljubljana Pediatrična klinika, Služba za otroško in mladostniško psihiatrijo, Ljubljana, Slovenija

prispelo / received: 2.6.2021 sprejeto / accepted: 9. 9. 2021

Knez M, et al. Vloga medicinske sestre pri obravnavi otrok z nesamomorilnim samopoškodbenim vedenjem in spektroavtistično motnjo ter posebnosti dajanja zdravil na oddelku za otroško psihiatrijo. Slov Pediatr 2021; 28(4): 223-227. https://doi. org/10.38031/slovpediatr-2021-4-06. 